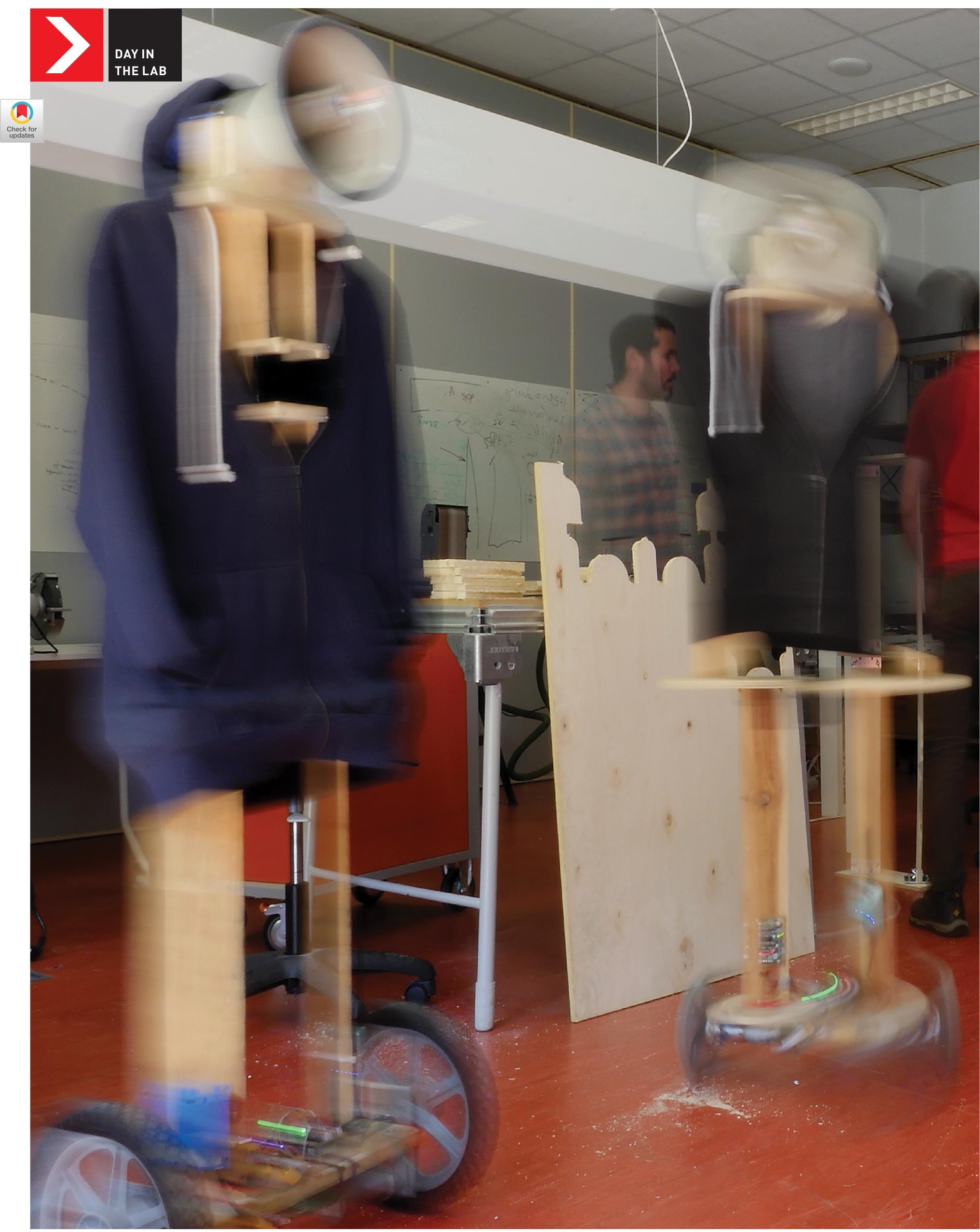




\section{Critical Technical Practice Lab, M-ITI}

As told by Chris Csíkszentmihályi

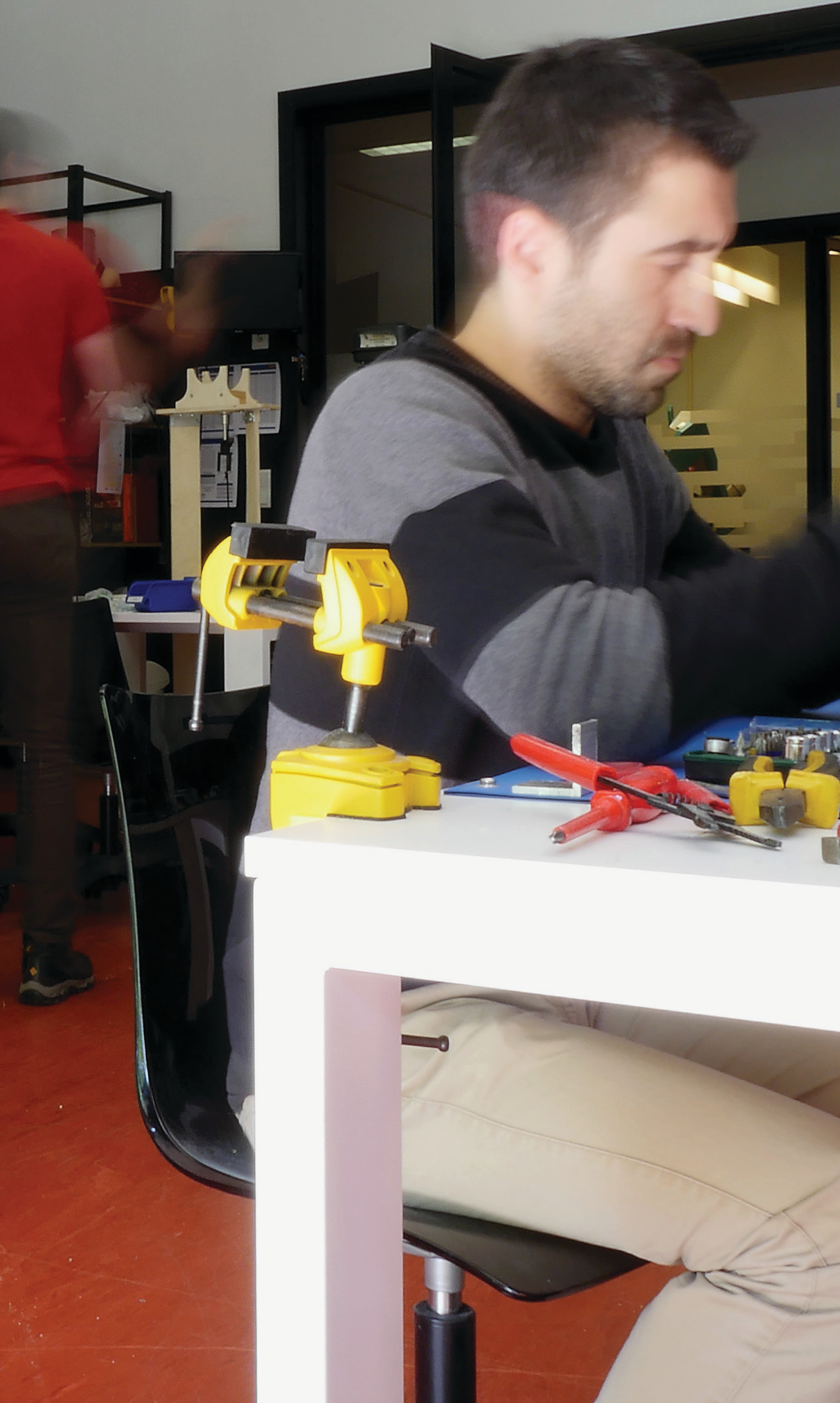

H ow do you describe your lab to visitors? The Critical Technical Practice (CTP) Lab at the Madeira Interactive Technologies Institute (M-ITI) is a multi-scale, multi-purpose lab+shop for research and education, tailored to the extremity of our location: a lovely small island in the middle of a big ocean. On this paradisiacal, warm, and verdant rock, we are trying to reimagine the possibilities of sociotechnical systems. Our parent organization, M-ITI, has a strong HCI reputation, with a foundation in CS and EE. Its founders recognized the importance of art, the humanities, and the social sciences for excellence in technical work and sought European funding to leapfrog into these areas. The lab is a place to experiment with these reconfigurations and to ensure that the $H$ in M-ITI's HCI is as robust as the $C$.

\section{What is a unique feature of your lab?} Location, location, location. Amazon Prime takes two weeks minimum; we are constrained by lead times and supply chains, but constraints drive creativity and we enjoy the challenge. As our most important work is deployed and scaled rather than merely prototyped for demo or exhibition, we also need to be able to make working parts when they are critical. This is why we have a lathe and an excellent CNC mill; we often make metal sprockets or gears, and molds for hard plastic parts. There is a lot of plywood and metal, not much foam core or acrylic. No 3D printer! We might build one, but we think these printers promote laziness when it comes to actually understanding how something might be built. We encourage mold making with our CNC mills, making jigs and machines to make things, and thinking about how an object would be manufactured.

As with our current projects in Uganda and Cabo Verde, we enjoy the challenge of thinking about how designs can be implemented with locally available materials and skills in different parts of the world. Our protest robots use wood from shipping pallets (and hoodies); discarded juicers and motorbikes litter our shelves. At the same time, we are investigating supply chains and energy on the island, looking at the cycle from import to 

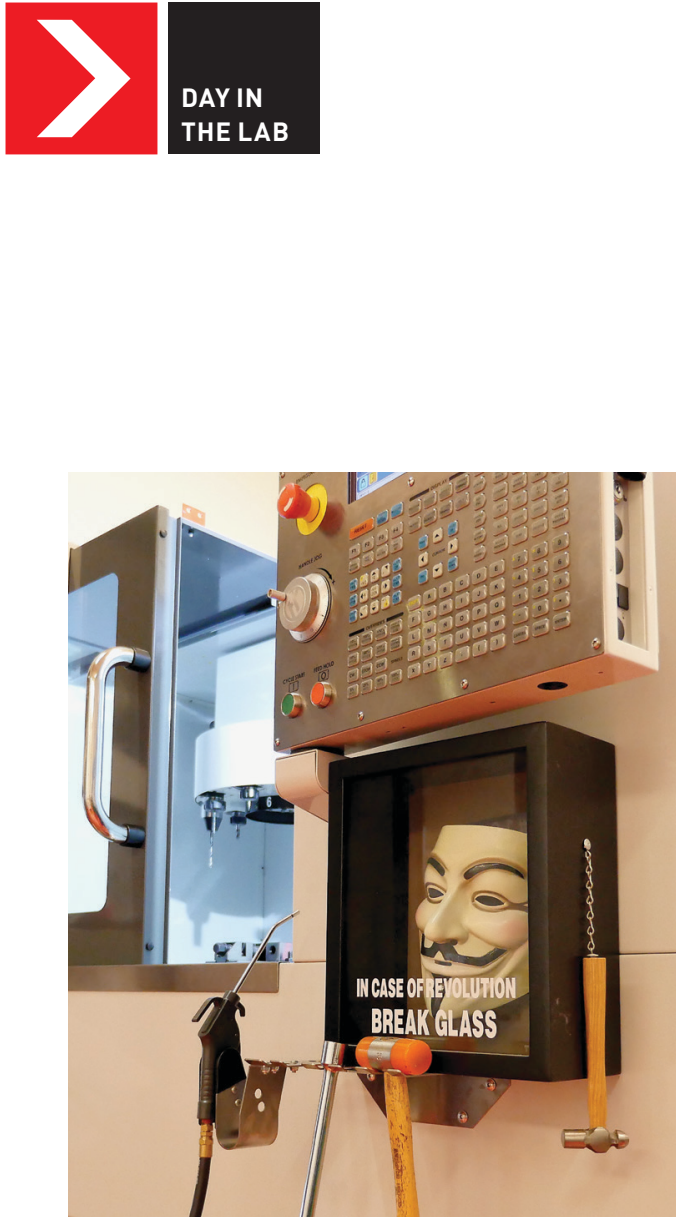

$\rightarrow$ We take safety seriously.

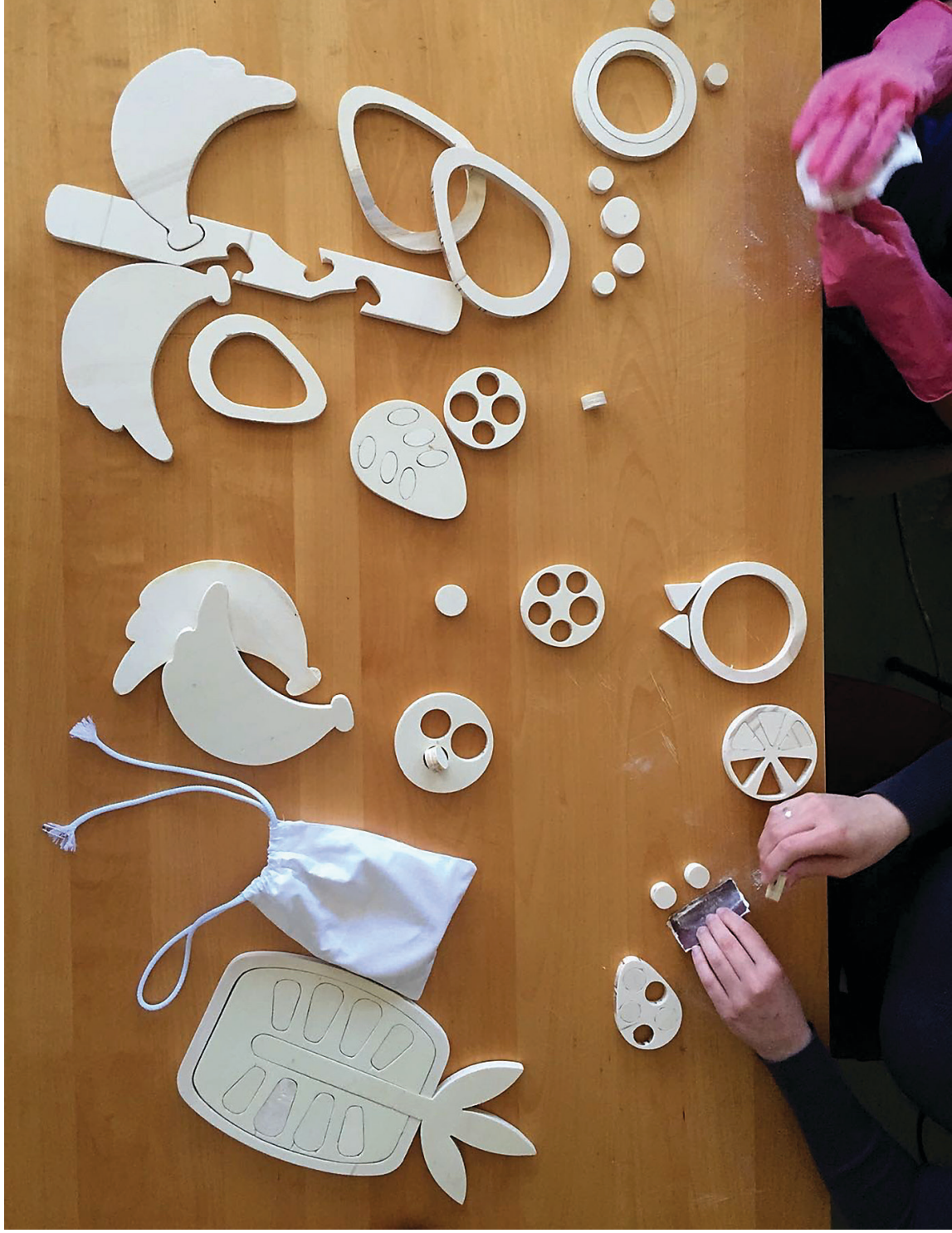

$\rightarrow$ Products of a class on locally inspired wooden toys, organized by U. Madeira design faculty and led by Prof. Sergio Lemos, fabricated in the CTP shop at Madeira-ITI. garbage, and trying to extract useful waste throughout the process. We are a long way from sustainability, but the gripping remoteness and precarity of our beautiful location makes sustainability an ever-present concern, and we are addressing it from an unusual perspective.

\section{How many people are in the lab, and what is the mix of backgrounds and} roles? We built the lab to conduct our own research but also as a service to the greater community, embracing other researchers at M-ITI, the scientists at the Madeira Ocean Observatory, and other faculty at the adjacent university. Altogether that means we're extremely heterogeneous, including American CMU/M-ITI MHCI students who spend their thesis year with us; Madeiran students who are the first in their families to go to college; a Ph.D. candidate from Uganda; an STS postdoc from Jamaica - indeed, students and postdocs from every continent. Europe has put a lot of energy into mobility, and the lab reflects this.

\section{What is one feature of your lab that} you could not do without? The massive powered subwoofer.

What is the one thing you see as most important about the work you do there? We see technology as politics by other means, and we derive our designs by reading STS, postcolonial theory, and engaging in long-term interactions with communities. A lot of our thinking references the strengths of southern Europe and its response to austerity and global finance: What are technologies of autonomy and solidarity? But Madeira is closer to Africa than it is to Europe, and has been a historical nexus between the Atlantic continents. Unfortunately, during the 500-year war on Africa by Europe, Madeira was a sort of laboratory for prototyping slavery and extraction - the first sugar plantations and refinery were here, before the discovery of the Americas. We are trying to append this history by referencing African epistemologies in our work, and developing technologies with and for the Global South that are better than what we have in the West. This is obviously very different from the cozy bourgeois concerns of much speculative design. It is also more messy and requires a diverse and multidisciplinary team.

http://ctp.m-iti.org/interactions 
